\title{
“O PROBLEMA DE SÓCRATES": um exemplo da fisiopsicologia de Nietzsche
}

\author{
"The Socrates problem": an exemple of \\ Nietzsche's physiopsychology
}

Wilson Antonio Frezzatti Jr.

Doutor em Filosofia pela USP, Professor dos cursos de Graduação e Mestrado em Filosofia da UNIOESTE, Cascavel, PR - Brasil, e-mail: wfrezzatti@uol.com.br

\section{Resumo}

O objetivo deste artigo é interpretar o texto "O problema de Sócrates" de Crepúsculo dos ídolos utilizando como chave a definição de psicologia que aparece em Para além de bem e mal § 23: "psicologia enquanto morfologia e teoria do desenvolvimento da vontade de potência". Trata-se de uma autêntica fisiopsicologia, já que os impulsos, para Nietzsche, não são nem corpo nem alma, mas tendência de aumento de potência. Além do conceito de vontade de potência, a noção de vida, entendida como processo contínuo de autossuperação, é central para a fisiopsicologia nietzschiana. Livre das concepções de bem e mal absolutos, a investigação nietzschiana não considera as produções humanas boas ou más, mas sintomas da dinâmica de impulsos do organismo que as produz: saudável, se afirma a vida, ou mórbida, se a nega. No caso de Sócrates, sua filosofia metafísica é sintoma de doença (decadência ou anarquia dos instintos), pois rejeita o mundo e o corpo.

Palavras-chave: Decadência; Fisiopsicologia; Vontade de potência. 


\section{Abstract}

The aim of this article is to interpret "The Socrates' problem" (Twilight of the Idols) through the definition of Psychology that appears on Beyond Good and Evil § 23: "Psychology as Morphology and Theory of the development of the Will to Power". It is an authentic Physiopsychology, because, according to Nietzsche, the forces are neither body nor soul, but tendency of potency increase. Besides the concept of Will to Power, the notion of life (continuous process of auto-overcoming) is central in the Nietzsche's Physiopsychology. Free from the conceptions of absolute good and evil, the Nietzschean investigation doesn't consider that the human productions are good or bad, they are symptoms of the impulsional dynamics of the organism that produces them: healthy, if it affirms the life, or morbid, if it denies the life. In the case of Socrates, his metaphysical philosophy is symptom of disease (decadence or anarchy of the instincts), because it rejects the world and the body.

Keywords: Decadence; Physiopsychology; Will to power.

\section{Introdução}

Em Para além de bem e mal § 23, Nietzsche propõe uma nova psicologia livre de preconceitos morais: "psicologia enquanto morfologia e teoria do desenvolvimento da vontade de potência". Essa investigação, que no mesmo texto o filósofo alemão chama de fisiopsicologia, pode ser entendida como a análise da relação que as produções humanas estabelecem com a vida. Livre de concepções morais, ou seja, da noção de bem e mal absolutos, a investigação nietzschiana não considera as produções humanas boas ou más, mas sintomas da dinâmica de impulsos do organismo que as produz. Esses impulsos são quanta de potência e são a efetivação, enquanto vir-a-ser, da tendência de aumento de potência, isto é, da vontade de potência (Wille zur Macht). Para Nietzsche, o mundo nada mais é do que um fluxo eterno de mudança que se efetiva enquanto vontade de potência, ou seja, uma multiplicidade de impulsos que lutam por mais potência. Sendo apenas grau de potência, o impulso não é constituído pela substância extensa, nem pela substância pensante: não é corpo, nem alma. Por 
isso, a investigação psicológica, ou seja, da dinâmica dos impulsos, é chamada de fisiopsicologia. Morfologia porque investiga a hierarquia de impulsos resultante da luta por mais potência. Teoria do desenvolvimento porque tenta entender a dinâmica da variação da quantidade de potência e da formação contínua de hierarquias. Assim, uma produção cultural pode ser considerada produto de um organismo bem hierarquizado e com impulsos potentes e, portanto, saudável, ou produto de um organismo no qual os impulsos estão enfraquecidos e desorganizados e, portanto, doente.

Esses graus de saúde se revelam pela relação que suas criações estabelecem com a vida. Por exemplo, uma filosofia saudável afirma a vida enquanto que uma filosofia mórbida a nega. Afirmar ou negar a vida no sentido que Nietzsche a define: vida é mudança, movimento contínuo de autossuperação. Dessa forma, filosofia, arte, ciência ou qualquer outra produção humana são saudáveis se entenderem a vida enquanto fluxo contínuo de mudança, o que é sintoma de uma configuração de impulsos, isto é, de um organismo potente e bem hierarquizado. Criações humanas que necessitam de conceitos imutáveis, eternos e absolutos são doentias, negam a vida, e, assim, são sintomas de configurações de impulsos mórbidas.

Pretendemos mostrar que os conceitos acima apresentados estão claramente presentes e são aplicados na análise que Nietzsche faz de Sócrates em "O problema de Sócrates", no segundo capítulo de Crepúsculo dos ídolos (1888). Sócrates, para o filósofo alemão, é aquele que busca a verdade absoluta para além do vir-a-ser, despreza a mutabilidade das coisas e funda a metafísica entendida como dualidade de mundos. Como todos os grandes filósofos e sábios posteriores, o mestre de Platão fez um mau juízo da vida: ela não vale nada.

\section{O Crepúsculo dos ídolos e "O problema de Sócrates"}

O livro Crepúsculo dos ídolos ou como filosofar com o martelo (Götzen-Dämmerung oder wie man mit dem Hammer philosophirt) foi elaborado em meados de 1888, em Sils Maria, com parte do material acumulado para a produção de Vontade de potência (Wille zur Macht). ${ }^{1}$ Entre 26 de agosto e 3 de setembro desse mesmo ano, Nietzsche abandona efetivamente esse projeto,

\footnotetext{
A maioria das informações sobre os aspectos históricos da elaboração de Crepúsculo dos ídolos foi extraída de MONTINARI, M. Ler Nietzsche: o Crepúsculo dos ídolos. Cadernos Nietzsche, n. 3, p. 77-91, 1997.
} 
substituindo-o por um novo, em quatro livros: Transvaloração de todos os valores (Umwertung aller Werte). ${ }^{2}$ Inicialmente, o filósofo preparou um texto que juntava partes do que veio a ser depois Crepúsculo dos ídolos e $O$ anticristo, mas o primeiro tornou-se uma espécie de resumo de sua filosofia e o segundo, o primeiro livro do novo projeto. Sendo parte de seus últimos escritos, o livro é mais do que um resumo de suas ideias: Nietzsche o considera, apesar de ser uma pequena obra com dez seções, uma grande declaração de guerra (CI Prefácio). Uma guerra que nada mais é do que uma distração de uma pesada tarefa que o filósofo alemão se impôs, ou seja, um alívio para a seriedade da transvaloração de todos os valores. Tarefa própria de um psicólogo, cujo martelo não é utilizado apenas para demolir os ídolos eternos, mas para investigá-los, diagnosticá-los. No prefácio de Crepúsculo dos ídolos, escrito no mesmo dia do término de $O$ anticristo (30 de setembro de 1888), o martelo é um instrumento que toca os ídolos para ressoarem, como faz o médico que ausculta (aushorchen) o corpo do paciente, o músico com seu diapasão ou ainda o geólogo com sua pedra. ${ }^{3}$ Estamos diante do psicólogo que interroga o objeto de sua investigação acerca de seus sintomas. O som emitido pelos ídolos? Um ídolo que é considerado eterno, imutável e absoluto só pode emitir um tipo de som: o oco, ou seja, o vazio.

O texto foi concebido como o repouso, o ócio de um psicólogo. Este é, aliás, o primeiro título imaginado por Nietzsche para ele: Ociosidade de um psicólogo (Müssigang eines Psychologen). O ócio que se exerce com luta, com serenidade e alegria (Heiterkeit) no diagnóstico e na derrubada dos valores absolutos, produzidos por organismos mórbidos que não suportam a mutabilidade do mundo, o vir-a-ser. Em Ecce homo, o filósofo alemão fala sobre o novo título: "o que, no frontispício, significa ídolo é simplesmente o que até agora se chamou verdade. Crepúsculo dos ídolos - significa: a velha verdade aproxima-se de seu fim [...]" (EH Crepúsculo dos ídolos 1). Tarefa

2 Nietzsche não realiza a tetralogia proposta no fragmento póstumo 19 [8] de setembro de 1888: Livro I: $O$ anticristo. Ensaio de uma crítica do cristianismo. Livro II: $O$ espírito livre. Crítica da filosofia enquanto um movimento niilista; Livro III: $O$ imoralista. Crítica da mais funesta espécie de ignorância, a moral; Livro IV: Dioniso. A filosofia do eterno retorno. Sobre $O$ anticristo ser, ainda em 1888 , considerado como a realização de todo o projeto da transvaloração. BARROS, 2002, p. 21-25.

3 Montinari aponta que Nietzsche escreve Crepúsculo dos ídolos, e também Caso Wagner, sob seu entusiasmo da leitura de Degeneração e criminalidade (Dégénerescence et criminalité), do médico francês Charles Féré, aluno de Charcot. A relação entre decadência e doenças fisiológicas foi também pesquisada pelo filósofo alemão nos textos de Paul Bourget, Ernst Renan, irmãos Goncourt e Baudelaire (MONTINARI, 1997, p. 86-87). 
para a qual Nietzsche sente-se habilitado, pois seria o único a perceber que o caminho à verdade é uma via de decadência, de declínio de potência. Na ausência de meias palavras que caracteriza Ecce homo, ele afirma que só a partir de seu trabalho há esperança para a elevação da cultura (Cultur) - Nietzsche, o alegre mensageiro (froher Botschafter). Contra a seriedade do filósofo metafísico mórbido, o ócio do psicólogo nietzschiano saudável.

A guerra está explícita no título da primeira seção, um conjunto de 44 breves aforismos: Sprüche und Pfeile, isto é, Máximas e setas (ou flechas). O ócio é expresso logo no primeiro aforismo, ou seja, na abertura da obra: "Ociosidade é o início de toda psicologia. Como? Psicologia seria um - vício?" ["Müssiggang ist aller Psychologie Anfang. Wie? Wäre Psychologie ein Laster?"]. Por que a psicologia, como Nietzsche a entende, a qual pensamos ser a análise de sintomas, da relação que as produções humanas estabelecem com a vida, seria um vício? "É preciso alvejar a moral" (CI Máximas e setas 36). Em outras palavras, a investigação psicológica nietzschiana coloca-se em oposição à moral estabelecida, às virtudes estabelecidas. Isso porque, como já dissemos na introdução, a psicologia nietzschiana não se baseia na dualidade de opostos qualitativos absolutos, bem e mal, mas no pressuposto do estado fisiológico, ${ }^{4}$ ou melhor, fisiopsicológico do organismo, ou seja, na potência e na hierarquização de impulsos. Sendo assim, o psicólogo em seu ócio, isto é, na sua desvinculação dos valores estabelecidos, confronta-se contra os sistemas filosóficos e metafísicos tradicionais: "Eu desconfio de todos os sistematizadores [Systematikern] e afasto-me de seus caminhos. A vontade [Wille] de sistema é uma falta de retidão [Rechtschaffenheit]" (CI Máximas e setas 26). Sua psicologia é, portanto, um afastamento e um desafio à filosofia e aos valores tradicionais, um modo do filósofo alemão manter-se íntegro em sua defesa do vir-a-ser, da efetividade (Wirklichkeit).

4 O termo "fisiologia", no contexto de nossa investigação, não se refere apenas aos processos biológicos. O corpo ou a unidade orgânica nada mais é, para Nietzsche, do que um conjunto de impulsos, o que permite que o sentido nietzschiano de "fisiológico" seja ampliado. Assim, "processo fisiológico" passa a significar luta de quanta de potência (impulsos ou forças) por crescimento. Esse sentido de "fisiologia" não pode ser substituído como sinônimo pelo termo "biologia", pois ele passa a considerar não apenas corpos vivos, mas também o âmbito inorgânico e das produções humanas, tais como Estado, religião, arte, filosofia, ciência, etc. Em outras palavras, a "fisiologia", nesse sentido, extrapola o âmbito do biológico: mas ainda se refere a uma "unidade", ou seja, a um conjunto de forças ou impulsos (FREZZATTI Jr., Wilson. A fisiologia de Nietzsche: a superação da dualidade cultura /biologia. Ijuí: Editora da UNIJUÍ, 2006a. p. 68). 
Nietzsche não poderia escolher melhor o seu vício ou o de sua filosofia, o ócio ${ }^{5}$, pois a sua negação encontra-se na raiz mesmo da metafísica: Sócrates, ou melhor, a personagem Sócrates que aparece nos diálogos de Platão, entende a filosofia como um esforço de busca da verdade que afasta o vício do ócio. No Mênon, após a "demonstração" da doutrina da reminiscência por meio da "lembrança" do escravo de como construir um quadrado com o dobro da área, e, consequentemente, da prova da imortalidade da alma (PLATÃO, Mênon 82a85c), Sócrates diz ao jovem aristocrata da Tessália que, apesar de tudo, não pode dar certeza absoluta sobre a reminiscência e a imortalidade da alma, mas que algo pode ser provado com certeza por palavras e fatos: "Se acreditarmos que se deve buscar o que não sabemos, nós seremos homens melhores, mais valorosos e menos indolentes do que se acreditarmos que não é possível descobrir aquilo que não sabemos e que não devemos buscá-lo" (PLATÃO, Mênon 86b-c). A questão que desemboca na interrogação do escravo era se podemos encontrar aquilo que não conhecemos (PLATÃO, Mênon 80d-81a). O mestre de Platão tenta mostrar como isso é possível: nossa alma, por ser imortal, conhece as verdades, trata-se de utilizar o método correto para trazer à tona as reminiscências - a dialética ou a maiêutica. Acreditar que não podemos encontrar a verdade absoluta, como acreditam os sofistas e os retóricos, nos torna indolentes, ociosos, afastados da virtude, ou seja, afastados da verdade, da beleza e da felicidade. A busca filosófica, ao contrário da disputa dos sofistas e dos retóricos, que visaria apenas à vitória momentânea de um discurso, é a tentativa de se alcançar a verdade, a virtude e a beleza. ${ }^{6}$ No diálogo Fédon, aparecem argumentos semelhantes. Ao não convencer os tebanos Símias e Cebes, discípulos do pitagórico Filolau, sobre as características da alma (imortal, divina, absoluta, imutável, etc.), Sócrates lança mão do mito do destino das almas: aqueles que não possuem sabedoria e, portanto, virtude serão castigados de acordo

\footnotetext{
5 No fragmento póstumo 11 [107] de novembro 1887/março 1888, Nietzsche escreve: "Ociosidade é o início de toda filosofia. - por consequiência - filosofia é um vício?[...].” A troca de filosofia por psicologia, para nós, indica que o filósofo alemão pensava sua psicologia como sua própria filosofia, que, nesse período, baseava-se em duas interpretações sobre o vir-a-ser: a vontade de potência e o eterno retorno. Pensamos que um outro fragmento póstumo, 5 [70] do verão 1886/ outono 1887, contém essas ideias de modo telegráfico: "Niilismo: declínio de uma avaliação global (a saber, a avaliação moral), falta de novas forças interpretativas. Sobre a história dos valores. A vontade de potência e suas metamorfoses (o que até aqui era a vontade de moral: uma escola). O eterno retorno como martelo.” A psicologia de Nietzsche, a história dos valores e uma nova força interpretativa: vontade de potência e eterno retorno.

6 A igualdade entre verdade, virtude e beleza aparece em vários diálogos de Platão, por exemplo, Fédon, Górgias e República.
} 
com seus vícios quando chegarem ao Hades (PLATÃO, Fédon 107c-116a). Sendo a alma imortal, a única saída possível para seus males é tornar-se melhor, isto é, mais sábia. O filósofo, que está dedicado à alma e despreza os prazeres do corpo, como recompensa por sua busca incessante pela sabedoria e virtude, terá a felicidade dos bem-aventurados quando estiver morto, ou seja, quando sua alma se livrar do corpo. Apesar de ser "bela a recompensa e grande a esperança:"

[...] pretender que essas coisas sejam na realidade exatamente como as descrevi, eis o que não será próprio de um homem de bom senso! Mas crer que é uma coisa semelhante o que se dá com nossas almas e o seu destino - porque a alma é evidentemente imortal - eis uma opinião que me parece boa e digna de confiança. Belo será ter essa coragem! É preciso repeti-la como uma fórmula mágica [...]. (PLATÃO, Fédon 114cd).

O homem que seguir essa fórmula e desprezar os prazeres do corpo, "estranhos e nocivos", deve estar confiante no destino de sua alma após a morte: adornou sua alma com virtudes (temperança, justiça, coragem, verdade, libertação das paixões e dos vícios). Pouco antes de tomar a cicuta, Sócrates deixa uma tarefa a seus discípulos: serem zelosos nos cuidados com a própria alma. Ao que Críton responde: "Poremos todo o nosso coração, naturalmente, em conduzirnos dessa forma" (PLATÃO, Fédon 115bc). Eis o ócio de Nietzsche: livrar-se da tarefa socrática! Libertar-se das ideias de alma imortal, de bem e mal absolutos, da punição ou da recompensa eternos, da coincidência entre verdade e bem absolutos, de um outro mundo (transcendente) e de outros conceitos e valores cristalizados. Nietzsche pretende o antifinalismo do movimento do vir-a-ser, o ócio, ${ }^{7}$ que só é um vício na perspectiva da tradição religioso-metafísica.

\footnotetext{
Não podemos deixar de notar que, em um aspecto bem pontual, sem levar em consideração os respectivos contextos teóricos, podemos aproximar Nietzsche de Aristóteles: a filosofia surge do ócio. No caso do filósofo alemão, seu resgate do vir-a-ser só pode surgir com o desligamento dos valores vigentes. O filósofo grego, no Livro I da Metafísica, traça um espécie de história natural do conhecimento: sensação, memória, experiência (empeiría), arte (techné) e ciência (epistheme). A filosofia é a mais elevada das ciências, pois busca o conhecimento das primeiras causas e dos primeiros princípios. Aristóteles explica como surge cada grau de conhecimento e, sobre a ciência, diz: "Portanto, quando todas essas invenções [as artes que proviam as necessidades vitais ou a recreação] estavam estabelecidas, as ciências que não davam e nem visavam nem ao prazer nem às necessidades da vida foram descobertas, e primeiro nos lugares onde o homem primeiro começou a ter tempo livre. Por isso, as artes matemáticas foram estabelecidas no Egito; pois lá se permitiu que a classe sacerdotal vivesse no ócio” (METAFÍSICA, Livro I 981 b15-25).
} 
Não é à toa, portanto, que a segunda parte de Crepúsculo dos ídolos, logo após os aforismos, intitula-se "O problema de Sócrates" (Das Problem des Sokrates). Esse texto e as próximas cinco partes da versão final ("A 'razão' na filosofia"; "Como o 'mundo verdadeiro' acabou por se tornar fábula"; "Moral como contranatureza"; "Os quatro grandes erros"; e "Os 'melhoradores' da humanidade") faziam parte dos planos da obra abandonada "Vontade de potência", datados do período entre o início e o verão de 1888 e organizados de forma diferente. Esboços de "O problema de Sócrates" aparecem, por exemplo, no fragmento póstumo 14 [92] da primavera 1888. Sócrates, junto com Platão, é mencionado no fragmento intitulado "Filosofia como décadence", 14 [94] da primavera 1888, e, junto com Pirro, em "Crítica à filosofia", 15 [5] da primavera 1888, no qual a filosofia também é vista como decadência. No fragmento póstumo 16 [73] da primavera/verão 1888, o título "O problema de Sócrates" também aparece. Em todos esses excertos, verdade e moralidade estão relacionadas. De modo muito sucinto, podemos dizer que a equação "Verdade = Bem" é vista, por Nietzsche, como sintoma de decadência. Dessa forma, podemos considerar que "O problema de Sócrates" faz o diagnóstico de Sócrates por meio da análise de seus sintomas, enquanto que as partes seguintes desenvolvem as características de alguns dos principais sintomas dessa decadência: a razão como idiossincrasia dos filósofos, a falta de sentido histórico, a crença nos conceitos eternos e absolutos; a dualidade metafísica mundo aparente / mundo verdadeiro; a moralidade como inimiga da vida, do crescimento de potência; a crença no princípio de causalidade; e a crença de que a domesticação (Zähmung) do homem, ou seja, o enfraquecimento de seus impulsos, promove sua elevação (Erhöhung), seu melhoramento (Verbesserung).

\section{O problema de Sócrates: a decadência dos impulsos}

O aforismo 39 de "Máximas e setas" parece estar diretamente ligado ao primeiro parágrafo de "O problema de Sócrates": "O desiludido fala. - Eu procurava por grandes homens [grossen Menschen], eu sempre encontrava apenas macaqueação [Affen] de seu ideal”. Ao observar os grandes sábios da humanidade, Nietzsche diagnostica que eles não eram grandes homens, pois sempre tiveram o mesmo juízo sobre a vida: ela não vale nada (CI O problema de Sócrates 1). Portanto, são doentes: a negação da vida é sinal de morbidade, de impotência e/ou falta de hierarquização dos impulsos ou forças. Essa avaliação sobre a vida expressa cansaço vital, o que é testemunhado pelas próprias últimas palavras de Sócrates: "Viver - significa estar há muito doente: eu devo um galo 
a Asclépio Salvador." ${ }^{8} \mathrm{Na}$ antiga Grécia, os doentes dormiam nos templos de Asclépio, figura mitológica associada à medicina, esperando a cura, e era costume o paciente sacrificar um galo em homenagem a ele quando curado. Dessa forma, podemos entender que, ao morrer, Sócrates estava sendo curado de uma doença - sua própria vida. ${ }^{9}$ Essa conclusão é reforçada pela concepção socrática de filosofia apresentada no Fédon. O corpo, a movimentação e a mutabilidade das coisas sensíveis turbam a alma e impedem que ela atinja a verdade (as Idéias, eidos). Aprender a filosofar é aprender a morrer em vida, ou seja, a separar o corpo da alma, a fim de que esta siga seu caminho diligente até o conhecimento verdadeiro (PLATÃO, Fédon 63e-69e). Em outras palavras, purificação da alma e rejeição do corpo e do mundo. O cansaço de Sócrates era consequência de impulsos impotentes e anárquicos, decadentes, que não suportam a inconstância da efetividade (Wirklichkeit), pois seu movimento pode facilmente desagregar configurações de impulsos fracas. O mestre de Platão não é um caso único, a negação da vida é feita pelos "mais sábios [Weisesten] de todos os tempos". ${ }^{10}$ Isso mostra que o diagnóstico nietzschiano não é leviano: todos eles são décadents, está formado um consensus sapientium (consenso de sábios). A própria sabedoria (Weisheit) é mórbida: como um corvo é atraída pelo mais sutil cheiro de carne em decomposição (CI O problema de Sócrates 1). A sabedoria da tradição, ou seja, a busca de algo fixo (a verdade absoluta), da ausência de movimento, é expressão de um instinto de morte, de destruição. O consensus sapientium mostra que os sábios tinham em comum sua condição fisiológica (uma configuração de impulsos fraca e/ou desorganizada) e não que tinham razão quanto à verdade (CI O problema de Sócrates 2).

Esse consenso nos revela mais um aspecto, desta vez do procedimento nietzschiano: Sócrates serve como um modelo da condição fisiológica dos grandes sábios. Com isso queremos dizer que, mais do que

8 Nietzsche refere-se ao último instante de Sócrates conforme consta no diálogo Fédon: "Sócrates já se tinha tornado rijo e frio em quase toda a região inferior do ventre, quando descobriu sua face, que havia velado, e disse estas palavras, as derradeiras que pronunciou: 'Críton, devemos um galo a Asclépio; não te esqueças de pagar essa dívida'” (118a).

9 Em, GC Sócrates moribundo 340, Nietzsche aborda também as últimas palavras de Sócrates: "Será possível? Um homem como ele, que viveu jovialmente e como um soldado à vista de todos - era um pessimista? Ele havia apenas feito uma cara boa para a vida, o tempo inteiro ocultando seu último juízo, seu íntimo sentimento! Sócrates, Sócrates sofreu da vida!" (Tradução de Paulo César de Souza).

10 A expressão "os mais sábios de todos os tempos" refere-se a um poema de Goethe, Canção copta (Koptisches Lied) (nota 22 da tradução de Paulo César de Souza de Crepúsculo dos ídolos). 
uma análise do Sócrates histórico, Nietzsche investiga os sintomas de um tipo, aquele cuja degeneração impulsional provoca a exacerbação da racionalidade. "Sócrates", aqui, designa uma população de configurações de impulsos cujos sintomas de decadência são semelhantes - produzem a filosofia metafísica dualista.

Apesar das considerações que apresentamos acima sobre os grandes sábios, o filósofo alemão propõe-se a verificar essas afirmações: "esses mais sábios de todos os tempos devem ser observados de mais perto" (CI O problema de Sócrates 1). Assim, os parágrafos restantes (2 a 12) farão uma análise fisiopsicológica, ou seja, uma investigação dos sintomas da decadência daquele que Nietzsche considera o paradigma dos grandes sábios: "Sócrates".

\section{A análise fisiopsicológica do tipo "Sócrates"}

Platão e Sócrates são reconhecidos por Nietzsche como sintomas de declínio (Verfalls-Symptome). Não apenas sinais, contudo, mas também instrumentos da decadência grega (CI O problema de Sócrates 2). Por isso, são falsos gregos, antigregos. Lembremos que Sócrates, em $O$ nascimento da tragédia (1871), é apontado como mentor daquele que "assassinou" o esquema trágico (a união entre os impulsos apolíneos e dionisíacos), Eurípides, ao desfigurar a participação do coro dissonante. Com a destruição da verdadeira tragédia, inicia-se a busca incansável pela verdade absoluta: temos aqui a imposição de uma filosofia teórica em detrimento da sabedoria trágica. O conhecimento da efemeridade e da mutabilidade do homem e do mundo e a aceitação da finitude são substituídos pela crença de que é possível encontrar um critério único e absoluto para nos guiar, tanto para a verdade quanto para a virtude. Esse é o motivo de Sócrates ser um antigrego: foi o responsável por criar um estilo - teórico - que se opunha àquele da cultura grega elevada (aristocracia guerreira) - o trágico. O socratismo estético ("tudo deve ser inteligível para ser belo," NT 11) e moral ("tudo deve ser consciente para ser bom”, NT 12) substitui a experiência (Versuch) trágica. Já no primeiro texto filosófico publicado de Nietzsche, temos um diagnóstico da doença de Sócrates:

A sabedoria instintiva [o daimon de Sócrates] mostra-se, nessa natureza tão inteiramente anormal, apenas para contrapor-se, aqui e ali, ao conhecimento consciente, obstando-o. Enquanto, em todas as pessoas produtivas, o instinto é justamente a força afirmativa-criativa, e a consciência [Bewusstsein] se conduz de maneira crítica e 
dissuasora, em Sócrates é o instinto que se converte em crítico, a consciência em criador - uma verdadeira monstruosidade per defectum [por debilidade]! (NT 13).$^{11}$

A inversão das funções da consciência e do instinto resulta na supervalorização da verdade e da lógica.

Um sintoma dessa condição fisiológica ou fisiopsicológica é a negação da vida. Ao dizerem que a vida não vale nada, os grandes sábios estão avaliando-a, mas, para Nietzsche, essa avaliação não pode ser verdadeira (CI O problema de Sócrates 2). Eis aqui um conceito fundamental para entendermos a fisiopsicologia nietzschiana: a vida não pode ser avaliada. ${ }^{12}$ As apreciações, desfavoráveis ou mesmo favoráveis, da vida são apenas sintomas. Poderíamos acrescentar: a vida é para ser vivida, não podemos nos apartar dela para avaliála. Por isso, juízos sobre ela são apenas sintomas: de crescimento de potência e alto grau de hierarquização, se favorável; de declínio de potência e anarquia dos impulsos, se desfavorável. Mas o que é vida para o filósofo alemão? É um processo ou fluxo contínuo de luta entre impulsos por mais potência, em outras palavras, vontade de potência. É por esse motivo que o "fisiológico", em Nietzsche, não pode ser confundido com o biológico: o aspecto mais geral da realidade ou da efetividade (Wirklichkeit) é tendência a aumento de potência. É por isso também que a vida não pode ser avaliada, não há nada que possa estar fora do vir-a-ser para emitir valores sobre o próprio processo dinâmico. Sobre isso, Nietzsche assevera: “[...] o valor da vida não pode ser avaliado. Não por um vivo, pois ele é parte, é mesmo objeto de litígio, e não o juiz; não por um morto, por outros motivos" (CI O problema de Sócrates 2). Não há como um organismo se por à parte, condição para uma avaliação, do próprio processo vital. Porque a vida é um processo ininterrupto de busca por mais potência, ou seja, vontade de potência, podemos entender a fisiopsicologia nietzschiana como fazemos. Um organismo (conjunto de impulsos) que obtém sucesso, ou seja, mais potência, é saudável, enquanto outro que malogra é mórbido.

Neste momento de nosso artigo, gostaríamos de fazer uma pequena observação sobre um aspecto do texto de Montinari já citado anteriormente. Esse autor propõe que a desistência do projeto de Vontade de potência em favor de Transvaloração de todos os valores marca também uma mudança conceitual muito importante: a superação de um sistema baseado na vontade de

11 Segundo tradução de J. Guinsburg.

12 Souza, em sua tradução de "Crepúsculo dos ídolos" (nota 23), lembra que um dos alvos dessa crítica é o livro $O$ valor da vida (Der Wert des Lebens, 1865), de Eugen Dühring. 
potência pelo pensamento do eterno retorno (MONTINARI, 1997, p. 87-90). Este último conceito evitaria as características metafísicas do primeiro. Embora não seja o objetivo deste trabalho refutar ou corroborar a interessante proposta de Montinari, a noção de vontade de potência é central na leitura que fazemos da fisiopsicologia de Nietzsche, que, por sua vez, é a chave da interpretação que estamos fazendo de "O problema de Sócrates". Achamos que entender a fisiopsicologia nietzschiana como "morfologia e teoria do desenvolvimento da vontade de potência" (ABM 23) não faz dela uma sistemática ou sistema metafísico. A razão disso é o critério pelo qual os sintomas das configurações de impulsos ou forças são avaliados, um critério que, ele mesmo, não pode ser realmente avaliado: a vida. E vida é vontade de potência (ZA II "Da superação de si"). E mais, não há nada, de caráter inteligível, além de vontade de potência (ABM 36). Dizer que a vida não pode ser avaliada é afirmá-la tal qual faz o pensamento do eterno retorno: afirmar a vida nas alegrias e nas desgraças. Não vemos, portanto, diferença de status, neste contexto e segundo nossa interpretação da fisiopsicologia nietzschiana, entre a vontade de potência e o eterno retorno aplicados a "O problema de Sócrates."

Como todos os maiores sábios, Sócrates era decadente, avaliava a vida como um entrave, uma doença. Desse modo, eles não deveriam ser considerados sábios, mas o foram pela tradição metafísica (CI O problema de Sócrates 2). Em "O problema de Sócrates" § 3, temos alguns sintomas que uma perspectiva dualista consideraria físicos ou biológicos - é aqui que a influência de Féré aparece nitidamente. Além de plebeu, Sócrates era muito feio. A feiura, afirma o filósofo alemão, seria sintoma de mestiçagem ou de decadência. No primeiro caso, que também acaba sendo considerado um caso de decadência, insinua-se que o filósofo seria um falso grego, e, consequentemente, não aristocrata. No pensamento nietzschiano, o "nobre" é aquele que afirma a vida e "plebeu", aquele que a nega. Um desenvolvimento decadente poderia produzir criminosos. A tendência criminosa de Sócrates teria sido percebida em seu rosto por um estrangeiro, o qual disse que o filósofo era um monstro e que possuía todos os vícios - o que não foi contestado. ${ }^{13}$

13 Em Tusculanas IV e V, Cícero relata o seguinte episódio: o fisionomista trácio Zópiro, considerado o introdutor da fisiognomia, teria dito a Sócrates que ele era uma caverna para todos os piores desejos: mulherengo, estúpido, idiota, etc. O filósofo teria respondido: "Isso é verdade, mas me tornei senhor sobre todos esses desejos". Nietzsche utiliza essa resposta como indício de que Sócrates sabia de sua doença: a anarquia dos impulsos (CI O problema de Sócrates 9). 
Essa profusão de vícios indica anarquia de instintos, ou seja, segundo nossa interpretação, uma configuração de impulsos na qual nenhum prevalece e domina os outros, o que revela decadência. Além disso, mais sintomas são apresentados em "O problema de Sócrates" § 4, os quais poderiam ser considerados psicológicos ou morais. São eles: alucinações auditivas (o daimon), exagero nas atitudes (a exacerbação da lógica, por exemplo), a maldade do raquítico (provavelmente a ironia socrática). Porém, o sintoma mais bizarro é a equiparação "Razão $=$ Virtude $=$ Felicidade", pois se contrapõe à cultura grega elevada. ${ }^{14}$ Essa equação, que iguala verdade e bem absolutos com a felicidade, denuncia a necessidade de valores fixos em detrimento da aceitação do vir-a-ser, a incapacidade do organismo decadente suportar sua própria finitude e mudança.

Em lugar do gosto "aristocrático" pela luta e da vivência trágica (dionisíaca), a filosofia socrática oferece a dialética (CI O problema de Sócrates 5 e 6). O filósofo alemão vê isso como a ascensão da "plebe", isto é, daqueles que negam a vida, dos decadentes. Daí a acusação contra Sócrates de corromper a juventude: a dialética não participa das boas maneiras. Não é próprio do estilo aristocrático expor as razões de seus atos e pensamentos. O "nobre" (o grande homem) ordena, não precisa provar ou fundamentar nada. Se a dialética era ridícula aos olhos dos helenos antigos, por que foi levada a sério? Porque não havia nenhuma outra saída para a decadência dos impulsos daqueles que a criaram. Mas o mais importante: Sócrates e seus seguidores não eram os únicos decadentes, Atenas era decadente (CI O problema de Sócrates 9). A dialética, para Nietzsche, é tão ineficaz que seu uso só se justifica quando não há outro instrumento, quando a situação é desesperadora. Ela é a tentativa desesperada de configurações de impulsos em dissolução para encontrar um porto seguro, ou seja, para deter o vir-a-ser, para encontrar algo de fixo (os conceitos eternos e absolutos) e manter as coisas como são. Enfim, tenta-se deter a consumação da decadência, o próprio desaparecimento.

A dialética é mais do que um recurso desesperado de conservação do mesmo: é uma forma de vingança (CI O problema de Sócrates 7). Os decadentes ressentem-se contra aqueles cujos impulsos estão em crescimento de potência (os "nobres"), que precisam ser despotencializados (depotenzieren).

14 Não apenas à sabedoria trágica, mas também ao espírito aristocrático. Sobre a oposição entre o nobre Cálicles e Sócrates, no diálogo Górgias, FREZZATTI, 2006c. Numa variante, no manuscrito Mp XVI 4, Nietzsche escreve: "A equação mais antiga seria a seguinte: Virtude $=$ Instinto = Inconsciência radical” (COLLI; MONTINARI, 1996, p. 119; KSA 14, p. 414). 
Ao ridicularizar seu interlocutor, pois ele deve provar que não é irracional, a dialética mostra que é impiedosa. Entretanto, apesar de todas suas deficiências e seus problemas, esse procedimento, assim como Sócrates, produziu fascínio. O esperto filósofo utilizou, de forma atraente - erótica $^{15}$-, do gosto grego pela disputa (agon), atraindo também, assim, os "nobres": a dialética é uma nova e erótica espécie de agon (CI O problema de Sócrates 8).

Contudo, como, apesar de sua feiura, de sua morbidez, de seu procedimento que afrontava o estilo "nobre", o mestre de Platão impôs sua filosofia decadente? Voltemos ao que dissemos antes: Sócrates não era o único organismo decadente - toda Atenas sucumbia em meio ao cansaço da vida. ${ }^{16}$ Ele descobriu que a sua decadência não era um caso isolado, mas que a anarquia dos instintos já estava instalada por toda a parte, na "nobreza" inclusive (CI O problema de Sócrates 9). A grande esperteza socrática foi perceber que sua estratégia de conservação serviria como remédio para todos. Na luta de impulsos por mais potência, todo impulso tende a ser senhor, a dominar os outros, mas, na anarquia de impulsos, não há nenhum que consiga isso. A cultura ateniense tornava-se descaracterizada, sem estilo próprio, tudo passava a valer com o mesmo peso e qualquer influência estrangeira acabava se sobressaindo. Havia necessidade de algo forte para exercer o controle. Por isso, apesar de tudo, a proposta socrática vingou. Para acalmar a guerra entre os impulsos, algo que um organismo despotencializado não suporta, foi preciso a exacerbação do lógico, do teórico: tudo deve se submeter à verdade absoluta, que é fixa e racional, mas principalmente transcendente - remete a um outro lugar e a outras condições, perfeitos e não ameaçadores. Rejeita-se, com isso, os instintos humanos e o próprio mundo.

A exacerbação da racionalidade foi a única saída possível: a férrea ligação entre verdade e moral era o medicamento possível e eficiente. Sócrates, especialmente após morrer "pela verdade", torna-se um modelo a ser imitado, a luz da razão que age contra os apetites obscuros (CI O problema de Sócrates 10). Qualquer concessão aos instintos era associada à falsidade, ao vício, à feiura e, consequentemente, à infelicidade na vida após a morte.

15 A atração erótica pode ser entendida aqui no mesmo sentido encontrado em $O$ banquete de Platão: a atração, o desejo pela verdade. No entanto, há também um aspecto irônico de Nietzsche ao associar esse erotismo dialético a jovens e rapazinhos e definir Sócrates como um grande erótico (grosser Erotiker) (CI O problema de Sócrates 8).

16 Lembremos que, na época de Sócrates, Atenas estava em guerra contra Esparta e acabou sitiada por vários anos. Devido à sua força naval, o mar era sua porta principal. 
Entretanto, a solução socrática não era realmente uma cura. A receita do médico Sócrates era uma ilusão que se transformou naquela de todos os filósofos e moralistas: a crença de que se pode escapar da décadence por meio de uma guerra contra ela. Em outras palavras, não é possível o melhoramento do homem pela moral de valores absolutos. "Toda moral do melhoramento, também a cristã, foi um mal-entendido[...]" (CI O problema de Sócrates 11). Uma configuração de impulsos fraca não se torna potente devido ao homem se pretender "bom". O fluxo agonístico por mais potência não tem finalidade, não sofre influência externa (não há um "fora”!), não há arbítrio. É a própria dinâmica impulsional que modifica uma condição "fisiológica" ou fisiopsicológica. O que se conseguiu foi mudar a expressão da decadência, isto é, a maneira pela qual os sintomas apareciam. O que se pretendia cura, portanto, não era nada mais do que sintoma do próprio cansaço vital. A verdade a todo custo é sintoma de degeneração de um conjunto de impulsos, a tentativa de se fixar em algo e se conservar. Vida, porém, é vontade de potência, ou seja, movimento contínuo de autossuperação (ZA II Da superação de si). A negação dos instintos é doença, mas "enquanto a vida eleva-se, a felicidade é igual aos instintos" (CI O problema de Sócrates 11).

Sócrates, nos seus instantes derradeiros, disse que a vida era uma doença porque ele mesmo estava doente (CI O problema de Sócrates 12). E sabia muito bem disso. Não foi Atenas que condenou o filósofo, ele levou a Ekklesia a dar-lhe a cura definitiva - a cicuta. A decadência dos organismos (conjuntos de impulsos ou forças), ou seja, a impotência e/ou a falta de hierarquização dos impulsos, não é uma questão resolvida pela pretensa vontade humana. A luta dos impulsos por mais potência não determina para sempre os dominadores e os dominados, pois sua dinâmica incessante faz com que esses papéis se revezem. Um organismo decadente deve ser absorvido por hierarquias mais potentes: só assim pode superar sua condição e se modificar.

\section{A fisiopsicologia de Nietzsche: análise de sintomas e vida enquanto processo contínuo de autossuperação}

O procedimento da fisiopsicologia nietzschiana inicia-se na verificação dos sintomas e, através da relação que eles estabelecem com a vida, infere a condição "fisiológica" do organismo, isto é, de uma configuração de impulsos, seja ela um filósofo, uma cidade ou uma cultura. Eis o uso que Nietzsche faz da vontade de potência como interpretação e não como um 
fundamento: esse conceito não é um princípio metafísico do qual todo o resto é deduzido ou derivado. Por isso, a noção de vontade de potência não produz um sistema: o fisiopsicologista nietzschiano não verifica diretamente as condições físicas e o comportamento do objeto de investigação; no limite, não há medidas quantitativas de potência ou de grau de hierarquização dos impulsos. Nietzsche também não é um cientista.

O pressuposto axial desse procedimento é o conceito de vida enquanto processo contínuo de autossuperação. Os sintomas são quaisquer produções humanas: filosofia, arte, ciência, política, etc. As relações que essas produções estabelecem com a vida é o que define a condição de determinada configuração de impulsos - não o contrário, as condições do conjunto de impulsos não são o primeiro passo, a primeira verificação. O que tem sentido é "um organismo é doente porque nega a vida" e não "um organismo nega a vida porque é doente". Se, por exemplo, uma filosofia afirma o movimento do mundo, a finitude do homem e a mudança de valores, ela é produção de um organismo sadio e, portanto, com impulsos potentes e/ou bem hierarquizados. Se essa filosofia afirma a fixidez do mundo, a infinitude ou a divindade da alma humana e propõe valores absolutos, ela é produção de um organismo doente e, portanto, com impulsos fracos e/ou pouco hierarquizados. O que tentamos fazer neste artigo foi aplicar essas considerações na análise que o filósofo alemão faz de Sócrates, mais corretamente do tipo decadente Sócrates, em "O problema de Sócrates". Traduzimos nos termos acima a anarquia de instintos e a decadência socrática, o que Nietzsche não faz de modo explícito. O grau de hierarquização e a potência dos impulsos ("morfologia") e sua dinâmica de elevação ou de decadência ("teoria do desenvolvimento") estão presentes de forma nítida na segunda parte de Crepúsculo dos ídolos.

O termo "fisiopsicologia" (Physio-Psychologie), sugerido pelo próprio Nietzsche em ABM $\S 23$, traduz melhor o caráter do impulso ou da força - tendência a aumento de potência - do que a influência de suas leituras científicas sobre doenças. Assim, o filósofo alemão rompe com a dualidade corpo / alma e propõe uma investigação, que se confunde com sua própria concepção de filosofia, direcionada à elevação da cultura, ${ }^{17} \mathrm{o}$ que, para nós, significa propiciar a ação da capacidade criativa do homem, da capacidade de renovação de valores e conceitos.

17 Sobre a superação da dualidade cultura / biologia e as condições de elevação de uma cultura, FREZZATTI, 2006a, p. 245-291. 


\section{Referências}

ARISTÓTELES. Metaphysica. In: SMITH, J. A.; ROSS, W. D. (Ed.). The works of Aristotle. Oxford: Oxford, 1931.

BARROS, F. de M. A maldição transvalorada: o problema da civilização em $O$ anticristo de Nietzsche. São Paulo: Discurso Editorial; Ijuí: Editora da UNIJUÍ, 2002.

COLLI, G.; MONTINARI, M. Notes e variantes. In: NIETZSCHE, Friedrich. Crépuscule des idoles. Traduits par J.-C. Hémery. Paris: Gallimard, 1996.

FREZZATTI Jr., W. A. A fisiologia de Nietzsche: a superação da dualidade cultura / biologia. Ijuí: Editora da UNIJUÍ, 2006a.

. A psicologia de Nietzsche: afirmação e negação da vida como sintomas de saúde e doença. In: SOUZA, E. C. de; CRAIA, E. C.P. Ressonâncias filosóficas: entre o pensamento e a ação. Cascavel: EDUNIOESTE, 2006b. p. 65-82.

"O valor de um caracol" ou "O nobre nietzschiano: um elogio a Cálicles?”. Cadernos Nietzsche, n. 21, p. 29-46, $2006 \mathrm{c}$.

MONTINARI, M. Ler Nietzsche: o Crepúsculo dos ídolos. Cadernos Nietzsche, n. 3, p. 77-91, 1997.

NIETZSCHE, F. Assim falou Zaratustra. Tradução de Mário da Silva. São Paulo: Círculo do Livro, 1987.

O nascimento da tragédia. Tradução de J. Guinsburg. São Paulo: Companhia das Letras, 1992.

Ecce homo. Tradução de Paulo César de Souza. São Paulo: Companhia das Letras, 1995.

Más allá del bien y del mal. Traducción de A. Sánchez Pascual. Madrid: Alianza, 1997.

Sämtliche Werke: Kritische Studienausgabe (KSA). G. Colli und M. Montinari (Hg). Berlin: Walter de Gryter, 1999. 15 Bd.

A gaia ciência. Tradução de Paulo César de Souza. São Paulo: Companhia das Letras, 2001. 
Crepúsculo dos ídolos. Tradução de Paulo César de Souza. São Paulo: Companhia das Letras, 2006.

PLATÃo. Fédon. Tradução de J. Paleikat e J. C. Costa. São Paulo: Abril Cultural, 1972. (Coleção Os Pensadores).

Menon. In: COOPER, J. M. (Ed.). Complete works. Indiannapolis: Hackett, 1997. p. 870-897.

Recebido: 22/07/2008

Received: 07/22/2008

Aprovado: 28/08/2008

Approved: 08/28/2008 